\title{
THE ROLE OF CITES RESCUE CENTERS IN ORCHID CONSERVATION: CONCERNS AND QUESTIONS RAISED BY THE COLLABORATION ON AN ENDANGERED SLIPPER ORCHID (PAPHIOPEDILUM VIETNAMENSE O. GRUSS \& PERNER)
}

\author{
Thomas Mirenda ${ }^{1,4}$, Kyle Wallick $^{2} \&$ Robert R. GabeL ${ }^{3}$ \\ ${ }^{1}$ Smithsonian Institution Horticulture Services Division, Washington, DC 20013 USA \\ ${ }^{2}$ US Botanic Garden, Washington, DC 20032 USA \\ ${ }^{3}$ US Fish and Wildlife Service, Arlington, VA 22203 USA \\ ${ }^{4}$ Author for correspondence: mirendat@opp.si.edu
}

KEY Words: CITES, Paphiopedilum vietnamense, Vietnam

\begin{abstract}
The Convention on the International Trade in Endangered Species (CITES) is an international treaty currently adopted by 169 member countries to regulate international trade in over 30,000 species of animal and plants. Plants that are not transported in accordance with CITES requirements may be either denied entry, and sometimes abandoned, or subject to seizure by enforcement officials in importing coun-
\end{abstract} tries. Instead of being destroyed, abandoned or confiscated plants may be returned to the range countries or sent to CITES Rescue Centers, which are public museums or botanical gardens in member countries where the plants are cared for and cultivated. The role of these rescue centers has traditionally been educational, with the CITES plants used and/or displayed to the public in an exhibition or show aimed at raising public consciousness about orchids and their conservation issues. In many cases, the plants placed in rescue centers are unusual, extremely rare or even new species, and may consist of multiple wild-collected plants exhibiting natural population variability. These ex-situ 'populations' are often sufficiently diverse to maintain a vibrant and vigorous gene pool within a captive breeding scenario. Increasingly, as habitats are disturbed or destroyed, it has become apparent to many well meaning staff of botanic gardens and arboreta, particularly CITES rescue centers, to do more than provide care and display these species. Rescue centers should give consideration to the value of the genetic material entrusted to them, which over time and with the participation of multiple centers will become progressively more and more important for establishing co-operative ex situ breeding groups and might eventually serve as a source of plants to repopulate degraded habitats and reduce collection pressure. Propagation of these plants often involves resources, such as laboratories, related equipment and expertise unavailable at public gardens and could provide an opportunity for collaboration with commercial growers and private citizens that can easily provide these facilities and expertise. Particularly for showy, commercially desirable plants, such collaborators are often anxious to offer their services.

An example of this type of collaboration was the legal propagation and distribution of Paphiopedilum vietnamense from nine plants that arrived at the U.S. Botanic Garden in 1999 (the same year the species description was published). These plants were part of a larger seizure at the port of Seattle by the U.S. Fish and Wildlife Service. The U.S. Fish and Wildlife Service initially contacted the government of Vietnam which declined to repatriate the orchids. As a result, the orchids remained at the U.S. Botanic Garden under the sole jurisdiction of the U.S. Government. Subsequently, The Fish and Wildlife Service permitted a private orchid growing facility access to the $P$. vietnamense housed at U. S. Botanic Garden. Sibling crosses were made from the surprisingly genetically varied collection. The seeds were subsequently grown in vitro at the New York laboratory and flasks offered for sale with the condition that plants be offered to other botanical institutions. The benign intent of 
this collaboration was to offer legal plants in quantities that would serve to reduce collecting pressure on wild populations. Unfortunately, despite successful cultivation of the seedlings and the best of intentions, these propagated plants have still not been distributed to their intended recipients. This is attributable more to the vicissitudes of life than to anyone's greed or bad intent, but is indicative of the need for accountability when such collaborations are undertaken. Beyond this however, certain legal and ethical concerns are generated when such partnerships are entered into. Activities involving CITES Appendix-I plants need to be approached with the utmost consideration of the implications for the species' conservation.

There are three major conservation concerns that must be considered when making progeny of seized plants available commercially. First, the potential exists for unscrupulous collectors to continue to import illegally in order to obtain plants once they are introduced into commerce. The plants may actually be smuggled purposely to get legal plants in the trade. If not closely regulated, the legal plants are merely a smokescreen for continued pillaging of wild populations that threaten the species ultimate survival in its natural habitat. Second, regardless of whether the country of origin declines the return of the plants, they may still be opposed to the commercialization of their native species for profit, particularly profit that yields no benefit to the native country. Third, while the propagation and release of plants to commerce may reduce collection pressure, it does not eliminate all illegal trade if demand is high. Thus, the burden on law enforcement increases or becomes impossible as it becomes more difficult to separate legally and illegally received plants. If no legal plants are available, identification of the illegal is greatly simplified and law enforcement can be administered in an unclouded atmosphere.

This leads us to the question of what CITES rescue centers should do when they receive such desirable plants. The successes and concerns raised by this collaborative effort can serve as a guide for creating a protocol for conservation and propagation programs for any endangered orchid species that might be received by rescue centers in the future. In the meantime, the most significant role for Plant Rescue Centers continues to be the use of plants for display aimed at public education about conservation issues as well as the provision of the best possible horticultural maintenance and in-house propagation of the plants under their care, especially those taxa that are rare and endangered. Ideally, future conservation projects will involve in situ cooperation with the range country. Such efforts support the continued survival of these species in the habitats where they evolved and belong. And the efforts of CITES Rescue centers, instead of inadvertently contributing to wild extirpation can be more constructive, potentially reintroducing artificially propagated but genetically viable plants in protected areas when appropriate.

Thomas Mirenda holds a BS in Marine Biology from Occidental College but has been a lifelong horticulturist and orchidist, currently working as the Orchid Collection Specialist at the Smithsonian Institution.

Kyle Wallick received his MS in botany from the University of Oklahoma. He is currently Botanist at the U.S. Botanic Garden.

Robert R. Gabel has worked in the U.S. CITES Scientific Authority since1991, and has been Chief of the office since 2001. He has been employed by the U.S. Fish and Wildlife Service for 27 years, primarily working on endangered species research and captive propagation, and international wildlife trade (including plants). He is a member of the IUCN Orchid Specialist Group, the Conservation Committee of the American Orchid Society, and currently is the North American Regional Representative on the CITES Plants Committee. 